\title{
NAAG Reduces NMDA Receptor Current in CAI Hippocampal Pyramidal Neurons of Acute Slices and Dissociated Neurons
}

\author{
Richard Bergeron*,', Joseph T Coyle ${ }^{2}$, Guochan Tsai ${ }^{2}$ and Robert W Greene ${ }^{2}$ \\ 'Ottawa Health Research Institute, Ottawa, ON, Canada; '2Laboratory of Neuroscience, Department of Psychiatry, Harvard Medical School, \\ Belmont, MA, USA
}

\begin{abstract}
$\mathrm{N}$-Acetylaspartylglutamate (NAAG) is an abundant neuropeptide in the nervous system, yet its functions are not well understood. Pyramidal neurons of the CAI sector of acutely prepared hippocampal slices were recorded using the whole-cell patch-clamp technique. At low concentrations $(20 \mu \mathrm{M})$, NAAG reduced isolated N-methyl-D-aspartate receptor (NMDAR)-mediated synaptic currents or NMDA-induced currents. The NAAG-induced change in the NMDA concentration/response curve suggested that the antagonism was not competitive. However, the NAAG-induced change in the concentration/response curve for the NMDAR co-agonist, glycine, indicated that glycine can overcome the NAAG antagonism. The antagonism of the NMDAR induced by NAAG was still observed in the presence of LY-34I495, a potent and selective mGluR3 antagonist. Moreover, in dissociated pyramidal neurons of the CAI region, NAAG also reduced the NMDA current and this effect was reversed by glycine. These results suggest that NAAG reduces the NMDA currents in hippocampal CAI pyramidal neurons.

Neuropsychopharmacology (2005) 30, 7-16, advance online publication, 8 September 2004; doi: I 0. I 038/sj.npp. 1300559
\end{abstract}

Keywords: synaptic transmission; NMDA receptor; glycine; 7-chlorokynurenic acid; patch-clamp; hippocampus

\section{INTRODUCTION}

$\mathrm{N}$-Acetylaspartylglutamate (NAAG) is one of the most prevalent and widely distributed neuropeptides in the mammalian nervous system. NAAG is present in concentrations far exceeding those of established transmitters except glutamate and GABA (Coyle, 1997; Neale et al, 2000). Immunohistochemical studies indicate that NAAG is localized to many putative glutamatergic neuronal systems and to some nonglutamatergic systems (Moffett et al, 1989, 1994; Frondoza et al, 1990; Slusher et al, 1992; Tsai et al, 1993; Moffett and Namboodiri, 1995; Berger et al, 1995a; Passani et al, 1997). Electrical stimulation of NAAGcontaining axons evokes the release of NAAG in a $\mathrm{Ca}^{2+}$ dependent manner, consistent with its known localization to synaptic vesicles (Williamson and Neale, 1988; Tsai et al, 1988, 1990; Zollinger et al, 1994). NAAG is catabolized to $N$ acetylaspartate and glutamate by glutamate carboxypepti-

\footnotetext{
*Correspondence: Dr R Bergeron, Department of Psychiatry, Ottawa Health Research Institute, University of Ottawa, 725 Parkdale Avenue, Ottawa, ON, Canada KIY 4E9, Tel: + I 613729 0722, Fax: + I 613 729 1266, E-mail: rbergeron@ohri.ca

Received 4 February 2004; revised 30 July 2004; accepted 2 August 2004

Online publication: 3 August 2004 at http://www.acnp.org/citations/ Npp08030404047/default.pdf
}

dase II (GCP II), also known as $\mathrm{N}$-acetyl-alpha-linked acidic dipeptidase (NAALADase; Stauch et al, 1989). GCP II is identical to prostate-specific membrane antigen and intestinal folate hydrolase (Serval et al, 1990; Slusher et al, 1990; Carter et al, 1996; Halsted et al, 1998). GCP II, a cell surface peptidase with its active site in the extracellular space, is expressed primarily by astrocytes in the brain (Berger et al, 1995b; Carter et al, 1996; Berger and Schwab, 1996, 1999). NAAG fulfills most of the criteria for a neurotransmitter or modulator (Kandel et al, 2000); however, its physiological actions are not well understood.

Previous neurophysiological studies in cultured neurons indicated weak agonistic effects of NAAG at the $N$-methyl-Daspartate receptor (NMDAR), a subtype of ionotropic glutamate receptor, with an $\mathrm{ED}_{50}$ greater than $100 \mu \mathrm{M}$ (Westbrook et al, 1986; Trombley and Westbrook, 1990). While NAAG displaced the NMDAR ligand CGS19755, its affinity was 20 -fold less than glutamate, consistent with its low agonistic activity at the NMDAR (Valivullah et al, 1994). Indeed, the $\mathrm{IC}_{50}$ of NAAG determined against the binding of CGS-19755 is $0.88 \mu \mathrm{M}$ compared to glutamate's $\mathrm{IC}_{50}$ of $0.037 \mu \mathrm{M}$. NAAG has an $\mathrm{ED}_{50} 185 \mu \mathrm{M}$ in Xenopus oocytes expressing NMDAR1 receptors and an $\mathrm{ED}_{50}$ of greater than $300 \mu \mathrm{M}$ on cultures of mouse spinal cord neurons. In contrast, indirect evidence for antagonistic activity of NAAG was reported in acute slice preparations. Low 
concentrations of NAAG antagonized the NMDARmediated climbing fiber response in an acute cerebellar slice preparation (Sekiguchi et al, 1989) and prevented the development of long-term potentiation in the rat hippocampal slices (Grunze et al, 1996; Lea et al, 2001).

To clarify further the action of NAAG, we have examined its effects on isolated NMDAR mediated currents in CA1 pyramidal neurons of the rat in the acute hippocampal slice preparation and on dissociated CA1 pyramidal neurons.

\section{MATERIALS AND METHODS}

\section{Preparation of Acute Slices}

Slices $(400 \mu \mathrm{m}$ thick) of the hippocampus were obtained from anesthetized 45-50-day-old Long-Evans rats and were prepared using procedures as previously described (Bergeron et al, 1998). The slices were maintained fully submerged in a tissue chamber and continuously perfused with artificial cerebrospinal fluid (ACSF) of the following composition: (in $\mathrm{mM}$ ) NaCl: $124 ; \mathrm{KCl}: 2 ; \mathrm{MgCl}_{2}: 1.3 ; \mathrm{CaCl}_{2}$ : 2.5; $\mathrm{KH}_{2} \mathrm{PO}_{4}$ : 3; glucose: 10 and $\mathrm{NaHCO}_{3}: 26 \mathrm{mM}$. The osmolarity of the artificial cerebral fluid was $315 \mathrm{mOsm}$ and the $\mathrm{pH}$ adjusted to 7.35 . The ACSF was warmed to $30^{\circ} \mathrm{C}$ and gassed with a 95-5\% oxygen/carbon dioxide mixture.

\section{Electrophysiology}

Whole-cell patch-clamp recordings were obtained with a technique modified from Blanton et al (1989) with an Axopatch-1D amplifier (Axon Instruments, Burlingame, CA) using pClamp 8 software for data acquisition and Origin 5.0 software for data analysis. Briefly, borosilicate glass electrodes (resistance 8-12 M 2 ) were filled with patch solution containing (in $\mathrm{mM}$ ): K-gluconate: $120, \mathrm{KCl}: 10$, $\mathrm{MgCl}_{2}:$ 3, HEPES: 10, $\mathrm{K}_{2} \mathrm{ATP}: 2, \mathrm{Na}_{2} \mathrm{GTP}: 0.2$. The patch solution was buffered to 7.2 with $\mathrm{KOH}$ and filtered through a $0.2 \mu \mathrm{m}$ filter before use. Final osmolarity of the patch solution was $280 \mathrm{mOsm}$. Only cells with a resting potential $<-55 \mathrm{mV}$ and an AP overshoot of $>10 \mathrm{mV}$ were examined. Drugs were applied to the perfusion media using multiple lines that funneled into a single outlet near the recording area. Thus, any one of the multiple lines could be selected, thereby allowing for switching between different media with a time delay of about $20 \mathrm{~s}$. Postsynaptic currents were evoked with bipolar stimulation of the Schaffer collaterals. The stimulation intensity was adjusted to evoke postsynaptic current (PSC) with amplitudes in the range of 75-100 pA at $V_{\mathrm{h}}=-60 \mathrm{mV}$. Synaptic potential amplitudes, along with the input resistance, were displayed online during the course of each experiment. Access resistance (10-25 $\mathrm{m} \Omega$ ) was monitored online at regular intervals from the setting on the bridge balance, and neurons were eliminated if this parameter changed by $20 \%$.

\section{Isolation of NMDA Current}

We isolated the NMDAR component of the EPSC with the addition of a $\mathrm{GABA}_{\mathrm{A}}$ receptor antagonist, bicuculline $(20 \mu \mathrm{M})$, the $\alpha$-amino-3-hydroxy-5-methylisoxazole-4-propionic acid and kainic acid (AMPA/KA) receptor antagonist, 1,2,3,4-tetrahydro-6-nitro-2,3-dioxo-benzo[f]quinoxaline-7- sulfonamide (NBQX; $10 \mu \mathrm{M})$, strychnine $(0.5 \mu \mathrm{M})$ and the $\mathrm{GABA}_{\mathrm{B}}$ receptor antagonist 3-[[(3,4-dichlorophenyl)methyl] amino]propyl]diethoxymethyl)phosphinic acid (CGP 52432; $10 \mu \mathrm{M})$. For this series of experiments, a low $\mathrm{Mg}^{2+}$ $(0.1 \mathrm{mM})$ solution was used. In order to keep the same extracellular divalent cation concentration, $\mathrm{CaCl}_{2}: 3.7 \mathrm{mM}$ was included in the perfusion media. All chemical agents were obtained from Sigma-Aldrich except NAAG, which was purchased from Bachem Bioscience Inc.

\section{Binding Data}

Male Sprague-Dawley rats (200-250 g) were killed, and their cerebral cortices and hippocampi were rapidly removed. The tissue was homogenized in 10 volume $0.32 \mathrm{M}$ sucrose, $5 \mathrm{mM}$ Tris-acetate buffer ( $\mathrm{pH}$ 7.4) with a glass-Telfon homogenizer. The P2 pellet was subjected to hypotonic shock and was pelleted $(15000 \times g \times 15 \mathrm{~min})$ three times. The pellet was further washed with $5 \mathrm{mM}$ Tris-acetate buffer ( $\mathrm{pH} 7.4)$ and centrifugation $(20000 \times g, 15 \mathrm{~min})$ three times. The pellet was frozen overnight before the binding assay. Assays were performed in quadruplicate in polypropylene tubes containing $50-100 \mu \mathrm{g}$ of $\mathrm{P} 2$ membrane protein (determined by the method of Lowry et al, 1951), $5 \mathrm{nM}$ [3H]glycine $(41 \mathrm{Ci} / \mathrm{mmol}$; New England Nuclear) or $4 \mathrm{nM}$ [3H]MDL 105,519 (78.0 Ci/mmol; Amersham, Buckinghamshire, England) in $50 \mathrm{mM}$ Tris-acetate buffer ( $\mathrm{pH} 7.4$ ). Nonspecific binding was determined in the presence of $200 \mu \mathrm{M}$ D-serine. In total, $100 \mu \mathrm{M}$ strychnine was present in all $[3 \mathrm{H}]$ glycine binding assays to isolate the strychnineinsensitive component of glycine binding. For [3H]MDL 105,519 binding, the tubes were incubated at room temperature for $30 \mathrm{~min}$, and the assay was terminated by chilling on ice and rapidly filtering through glass fiber filters (Whatman GF/B). The filters were washed three times with $5 \mathrm{ml}$ ice-cold assay buffer, and radioactivity was determined by a $\beta$ counter with $10 \mathrm{ml}$ scintillation fluid. For the $[3 \mathrm{H}]$ glycine binding, the assay tubes were incubated at $4{ }^{\circ} \mathrm{C}$ for $30 \mathrm{~min}$ before centrifugation at $20000 \times \mathrm{g}$ for $30 \mathrm{~min}$ to separate free radioactivity from bound. The supernate was discarded and the pellet was superficially washed with icecold assay buffer. The pellet was solubilized in $0.4 \mathrm{ml} 2 \%$ sodium dodecyl sulfate before the quantification of radioactivity using a $\beta$ counter.

\section{Preparation of Dissociated Neurons}

The brain was rapidly removed and placed in cold $\left(\sim-5^{\circ} \mathrm{C}\right)$ saline that had been bubbled with $95 \% \quad \mathrm{O}_{2} / 5 \% \mathrm{CO}_{2}$. The following solutions (in $\mathrm{mM}$ ) were used: PIPES saline: $\mathrm{NaCl}$ 120, $\mathrm{kCl} 5, \mathrm{CaCl}_{2} 1, \mathrm{MgCl}_{2} 1$, D-glucose 25, PIPES 20 (piperozine- $N, N^{1}$-bis [2-ethasultonic acid]) $\mathrm{pH}$ 7.0. HEPES saline: $\mathrm{NaCl} 140 \mathrm{KCl} 5, \mathrm{CaCl}_{2}, \mathrm{MgCl}_{2}$ 1, D-glucose 24, HEPES 10 ( $\mathrm{pH}$ 7.4). DMEM: Dulbecco's modified Eagle's medium with HEPES 25, D-glucose 25.

The CA1 sector of the hippocampus was isolated using a scalpel blade to remove as many other surrounding structures as possible. The brain slices were manipulated with great care, avoiding the application of pressure to the CA1. A moist fine brush was used to transfer slices. The slices were placed in the central chamber and stirred at a rate sufficient to buoy them up and to prevent them from 
adhering to the stir bar. The chamber was held at $32^{\circ} \mathrm{C}$, and $95 \% \mathrm{O}_{2} / 5 \% \mathrm{CO}_{2}$ was introduced continuously. After $90 \mathrm{~min}$, the saline was removed and replaced with $10 \mathrm{ml}$ of PIPES saline. The chamber was allowed to come to room temperature, while continuously introducing $95 \%$ $\mathrm{O}_{2} / 5 \% \mathrm{CO}_{2}$.

The last step consisted of removing one slice from the chamber and placing it in $2 \mathrm{ml}$ of DMEM, held in a small glass vial. The slice was then triturated with two fine polished Pasteur pipettes having inner diameters of about $0.2 \mathrm{~mm}$. The tissue was triturated with the larger bored pipette at regular periods. When the slice became so disaggregated that it passed easily through the pipette, the trituration continued with a finer bored pipette at the same steady frequency until it finely disbursed. The whole solution was then transferred to the recording chamber. The neurons were allowed to settle on the bottom of the chamber before the DMEM was replaced with the HEPES saline, which was used during the recording. As dissociated neurons do not last much more than $2 \mathrm{~h}$, neurons were prepared just before recording.

\section{Statistical Analysis}

Data were collected using software pClamp 9 (Axon Instrument, Foster City, CA). Analyses were performed off-line with either the software OriginLab, version 7.5 or with IGOR (WaveMetrics Inc., Lake Oswego, OR). Statistical significance of the results was determined with paired $t$-tests (two-tailed). All values are expressed as means $\pm S E$.

\section{RESULTS}

\section{Synaptic Activity}

The CA3 input to CA1 pyramidal cells, mediated by the Schaffer collaterals, is glutamatergic (Amaral and Witter, 1989). The NMDA component of the evoked excitatory post-synaptic current (EPSC) was pharmacologically isolated with the AMPA/KA receptor antagonist, (NBQX; $10 \mu \mathrm{M})$, the $\mathrm{GABA}_{\mathrm{A}}$ receptor antagonist, bicuculline $(20 \mu \mathrm{M})$, and the $\mathrm{GABA}_{\mathrm{B}}$ receptor antagonist CGP 52431 $(10 \mu \mathrm{M})$ in low $\mathrm{Mg}^{2+}$ solution $(0.1 \mathrm{mM})$.

A first series of experiments was undertaken, in order to clarify the physiological action of NAAG. We have examined its effects on the amplitude of the isolated NMDAR currents in CA1 pyramidal neurons in voltageclamp mode, at $-60 \mathrm{mV}$ in a low $\mathrm{Mg}^{2+}$ solution. A doseresponse curve was generated from 1 to $500 \mu \mathrm{M}$. We found that from 1 and $10 \mu \mathrm{M}$, no significant effect was observed on the amplitude of the isolated NMDAR current. At doses in between 20 and $500 \mu \mathrm{M}$, in comparison to control, a reduction of approximately $80 \%$ of amplitude of the isolated NMDAR current was observed (Figure 1).

In the second series of experiments, we examined the effect of NAAG $(20 \mu \mathrm{M})$ selectively antagonized the NMDAR component of the EPSC $(P<0.005 ; n=12$; Figure $2 \mathrm{a}$ and $\mathrm{c})$. NAAG was without effect on the Schaffer collateralmediated AMPAR component of the EPSC, isolated with the NMDAR competitive antagonist, aminophosphoric acid (APV; $20 \mu \mathrm{M})$, and bicuculline $(20 \mu \mathrm{M} ; P>0.05 ; n=6$;

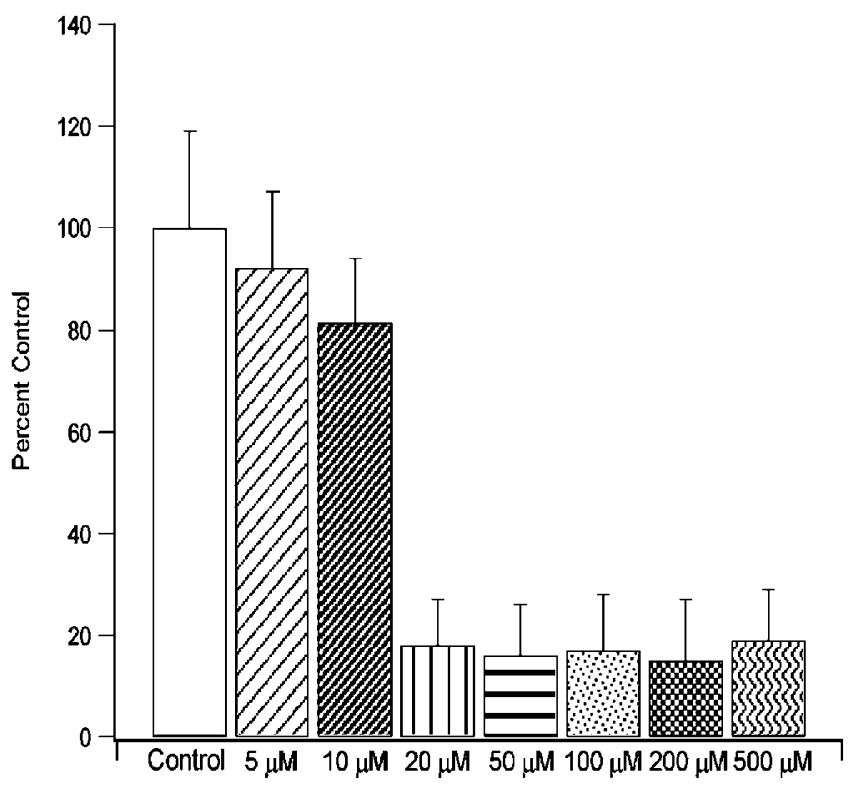

Figure I Dose-response curve of the effects of NAAG on NMDAR current. We have performed this first series of experiments in order to determine the minimal effective dose of NAAG that can antagonize the NMDAR current by at least $50 \%$ from the control. Using the voltage-clamp mode, we recorded CA! pyramidal neurons and we evoked EPSC by stimulating the Schaffer collaterals. We isolated the NMDAR component of the EPSC with the addition of bicuculline $(20 \mu \mathrm{M}), \operatorname{NBQX} ;(10 \mu \mathrm{M})$, strychnine $(0.5 \mu \mathrm{M})$ and CGP $52432(10 \mu \mathrm{M})$ in a low $\mathrm{Mg}^{2+}(0.1 \mathrm{mM})$ solution. For each dose, five neurons were recorded and the results were compared to the control.

Figure $2 \mathrm{~b}$ ). The antagonism of NAAG was also compared to the effect of APV and no significant difference was found between the reduction of the NMDAR current induced by APV or NAAG $(P>0.05 ; n=12$; Figure $2 \mathrm{c})$. There was an occlusion effect between NAAG $(20 \mu \mathrm{M})$ and APV $(20 \mu \mathrm{M})$ $(n=5$, data not shown).

The antagonism of NAAG $(20 \mu \mathrm{M})$ on the amplitude of the isolated current of the NMDAR was then studied in a voltage range from $-80 \mathrm{mV}$ to $+40 \mathrm{mV}$ and compared to the control. Figure 3 clearly shows that the blockade of NAAG on NMDAR current is present at voltages where NMDAR is open after the $\mathrm{Mg}^{2+}$ block is relieved.

To rule out an intracellular mechanism that may underlie the antagonism of NAAG on the NMDAR current, we carried two series of experiments using intracellular dialysis GTP- $\gamma$-S and GTP- $\beta$-S. The recorded cells were infused with GTP- $\gamma$-S and GTP- $\beta$-S $(1 \mathrm{mM})$. After patching a CA1 pyramidal cell, we kept the cell for more than $30 \mathrm{~min}$ in order to allow the diffusion of the compounds into the cell. After that delay, we did not observe any effect of GTP- $\gamma$-S and GTP- $\beta$-S by themselves on the NMDAR-mediated EPSCs. However, NAAG $(20 \mu \mathrm{M})$ induced a reduction on the amplitude of the isolated NMDAR current. In comparison to control experiments, we did not observe any significant difference in the reduction of the isolated NMDAR current when GTP- $\gamma$-S ( $1 \mathrm{mM} ; n=5$ or GTP- $\beta$-S $(1 \mathrm{mM} ; n=5)$ ) were dialyzed into the CA1 cells (data not shown). These results strongly suggest that intracellular mechanism is not involved in observable antagonism of NAAG on the NMDAR. 
a Effect of NAAG $(20 \mu \mathrm{M})$ on the Isolated NMDA EPSC

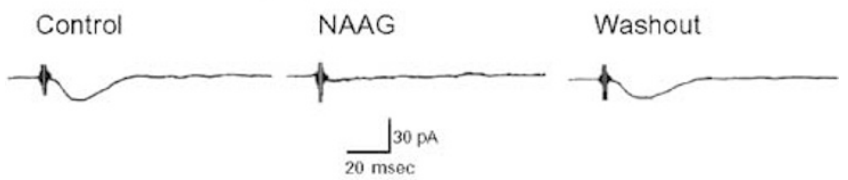

b Effect of NAAG $(20 \mu \mathrm{M})$ on the Isolated AMPA EPSC Before the application of NAAG

During the application<smiles>CCCCCCC</smiles>

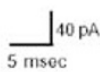
of NAAG

C

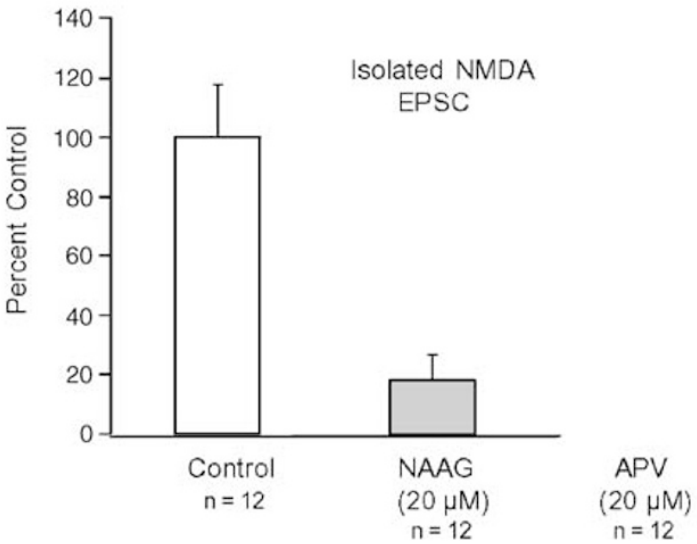

Figure 2 Synaptic activity of NAAG in the CAI area of the hippocampus. (a) Effect of NAAG on the isolated NMDAR currents in CAI hippocampal pyramidal neurons. The evoked-EPSC was first induced by bipolar electrical stimuli at $V_{m}=-60 \mathrm{mV}$ in a normal ACSF and than the NMDAR current was pharmacologically isolated. Neurons were recorded in a low $\mathrm{Mg}^{2+} \operatorname{ACSF}(0.1 \mathrm{mM})$ in the presence of $\mathrm{NBQX}(10 \mu \mathrm{M})$, bicuculline $(20 \mu \mathrm{M})$, CGP $52432(10 \mu \mathrm{M})$ and strychnine $(0.5 \mu \mathrm{M})$. Each trace is an average of 10 traces. The antagonistic effect of NAAG was reversible after 20 min of washout. (b) Effect of NAAG on the isolated AMPAR currents in CAI hippocampal pyramidal neurons. The evokedEPSC was also induced by bipolar electrical stimuli at $V_{m}=-60 \mathrm{mV}$ in normal ACSF and than the AMPAR current was pharmacologically isolated (see Methods). The application of NAAG did not modify significantly the amplitude of the EPSC. (c) Histogram of the ratio between the amplitude of the EPSC in control and the amplitude of the EPCS during the application of NAAG and during the application of APV. In both cases, the antagonistic effect of NAAG or APV was statistically significant $(p<0.005)$.

\section{Paired-Pulse Stimulation}

The depolarization-induced, calcium-dependent release of endogenous NAAG has been well demonstrated in several brain areas including the hippocampus. Our results showing that NAAG was without effect on the Schaffer collateral mediated AMPAR component of the EPSC (Figure 2b) suggests that NAAG has no presynaptic effect at CA1 synapses. To better characterize the selective postsynaptic effect of NAAG, paired-pulse stimulation was used, and the ratio of successive responses was measured. We observed reduced EPSC in both paired-pulse facilitations (pulse interval $60 \mathrm{~ms}$ ). The average paired-pulse ratios of EPSCs were $98.5 \pm 10.8 \%$ in the control and $92.2 \pm 9.8 \%$ in the experiments with NAAG, respectively $(P<0.005 ; n=14$; Figure $4 \mathrm{a}, \mathrm{b})$. These results suggest NAAG action on the

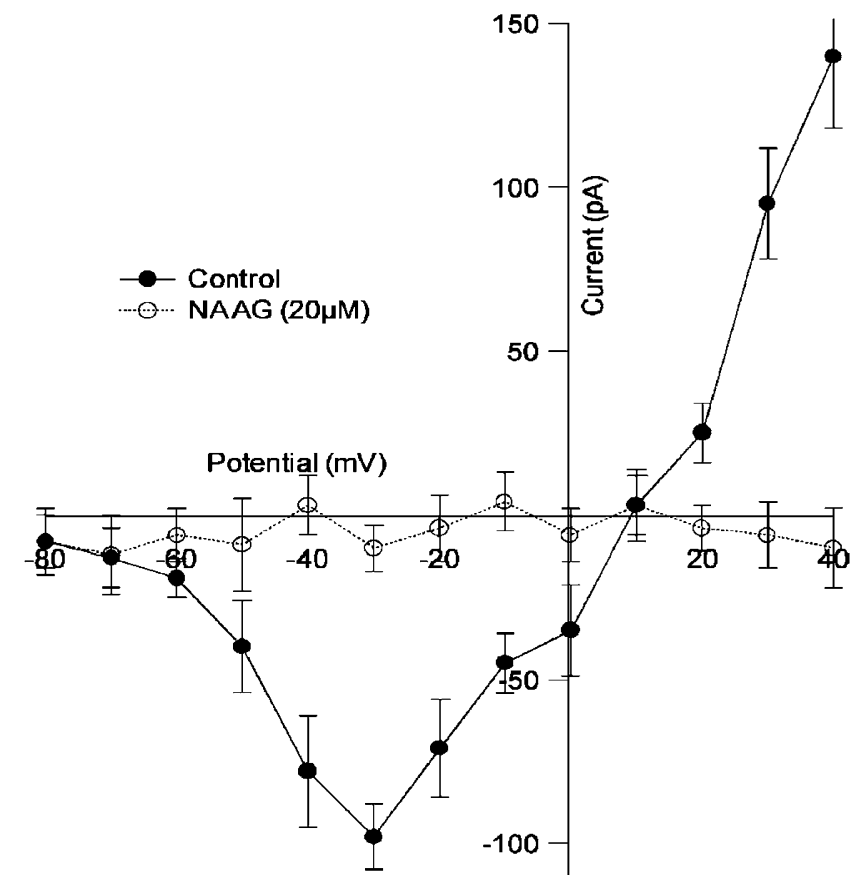

Figure 3 Voltage-dependent of NAAG antagonism on the NMDAR current. The antagonism of NAAG $(20 \mu \mathrm{M})$ on the amplitude of the isolated current of the NMDAR was investigated in a voltage range from -80 to $+40 \mathrm{mV}$. We measured the antagonistic effect of NAAG the NMDAR component of the evoked EPSC. We recorded IO CAI pyramidal cells. The NMDAR current was measured in the absence (control) and in the presence of NAAG. The results demonstrate that the blockade of NAAG on the amplitude of the isolated NMDAR current is present at voltages where NMDAR is open after the $\mathrm{Mg}^{2+}$ block is relieved.

NMDAR current of the CA1 neurons following the stimulation of the Schaffer collaterals to be postsynaptic but do not exclude a presynaptic effect.

\section{Local Application of NMDA}

To further clarify the mechanism of NAAG on the NMDAR, we applied NMDA using a picospritzer (from Parker Instrumentation). The major advantage of this technique is direct application of NMDA on the recorded neurons. NMDA $(100 \mu \mathrm{m})$ was included in the pipette, which was placed as close as possible to the recording electrode. After acquisition of a CA1 pyramidal neuron, NBQX, bicuculline, CGP 52432, strychnine and tetrodotoxin (TTX; $0.5 \mu \mathrm{M}$ ) were included in the ACSF. NMDA was applied for $500 \mathrm{~ms}$. The amplitude of the current induced by the local application of NMDA in control ACSF was averaged $(n=12,100 \%)$. NAAG $(20 \mu \mathrm{M})$ was then added to the ACSF for $15 \mathrm{~min}$ and we measured the new current induced by NMDA in the presence of NAAG $(n=12)$. Paired $t$-test was used to compare the two average currents. Application of NMDA induced an inward current of $420 \mathrm{pA} \pm 85.3 \mathrm{pA} \quad(n=12$; Figure $4 \mathrm{c}, \mathrm{d})$ in the control, $352 \pm 78.6 \mathrm{pA}(n=12$; $P<0.005$; Figure 3 ) in the presence of NAAG. This effect was highly significant $(P<0.005)$ and strongly suggests that NAAG antagonizes NMDAR. 
a
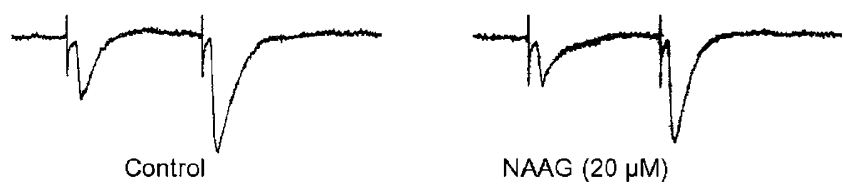

b

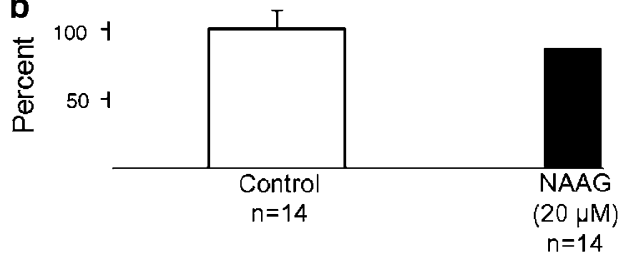

C

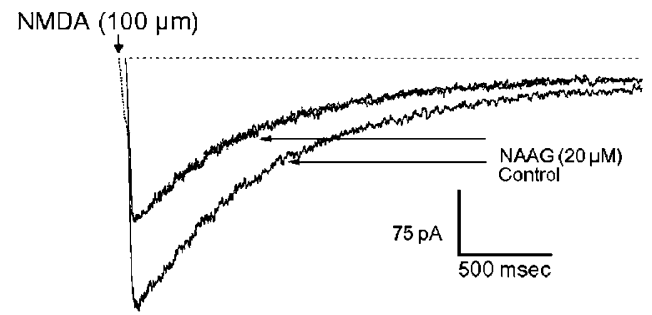

d

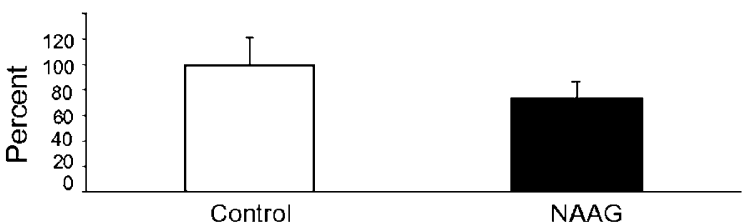

Figure 4 Effect of NAAG on paired pulse stimulation and following local application of NMDA in the CAI area of the hippocampus. (a) Responses were evoked by bipolar electrical stimuli at $V_{m}-60 \mathrm{mV}$ in pyramidal neurons. Two pulses of identical intensity were delivered with an interval of $60 \mathrm{~ms}$. Glutamatergic-evoked responses observed in normal ACSF, during application of NAAG $(20 \mu \mathrm{M} ; n=12)$, and after recovery from the drug are superimposed. Each trace is an average of 20 traces. (b) Histogram of the ratio between the amplitude of the second and the first evoked response (in control and during the application of NAAG respectively) is shown. This difference was not statistically significant $(p>0.5)$. (c) NMDA $(100 \mu \mathrm{M})$ was applied through a patch pipette positioned directly above the proximal dendrites. TTX $(0.5 \mu \mathrm{M})$ was present throughout the experiments. The neuron was voltage-clamped at $V_{m}=-60 \mathrm{mV}$. NMDA-evoked responses observed in low $\mathrm{Mg}^{2+}$ ACSF in control and during application of NAAG $(20 \mu \mathrm{M})$. Each trace is an average of four traces. Time base is $500 \mathrm{~ms}$. (d) The antagonist effect of NAAG was statistically significant and the results in a bar histogram.

The comparisons made between responses induced NMDA and NMDA plus NAAG does not rule out any direct effect of NAAG on the cell. To evaluate a potential agonistic effect of NAAG on the NMDAR, we have included NAAG at the dose of $20 \mu \mathrm{M}$ in the pipette and we have isolated pharmacologically the NMDAR. Local application of NAAG did not induce any effect when NMDA was not applied (data not shown). These results suggest that in the CA1 region of the hippocampus, NAAG by itself does not act as a partial agonist on the NMDAR as previously reported in culture cell paradigm (Westbrook et al, (1986)).

\section{Bath Application of NAAG/NMDA}

The mechanism responsible for NAAG's antagonistic action was examined using dose/response curve to NMDA. This was generated by addition of five different concentrations of NMDA ( $n=5$ cells for each concentration) to the superfusate. These experiments were carried out in the presence of NBQX, bicuculline, CGP 52432, strychnine and TTX in a low magnesium solution $(0.1 \mathrm{mM})$, in order to isolate the NMDAR-mediated current, while recording from CA1 pyramidal neurons with the whole-cell voltage-clamp technique. NMDA was applied until the amplitude of the NMDA-induced current reached a plateau ( $\sim 20 \mathrm{~s}$ in every case). The neurons' responses to the same doses of NMDA in the presence of NAAG $(20 \mu \mathrm{M})$ in the superfusate were then compared to the responses to NMDA alone.

Indeed, all five concentrations of NMDA without NAAG and all five concentrations of NMDA plus NAAG $(20 \mu \mathrm{M})$ were tested on different cells. In other words, 50 different cells were recorded for that series of experiments. The experiments were organized in the following way: (1) a slice received a 30 min washout, (2) a cell was recorded on the slice and NMDA was applied alone (3) on the same slice, another cell was recorded and NMDA plus NAAG was applied. After completing these two experiments, the brain slice was systematically removed, replaced by another one and the procedure was repeated.

Antagonism of NMDA by NAAG was only apparent at doses of NMDA greater than $30 \mu \mathrm{M}$ (Figure 5). Synaptic neurotransmission activates fewer NMDARs than bath applied NMDA and includes a desensitizing component. Both of these factors may have contributed to an apparent blockade of the synaptic response if: (1) the reduced synaptic NMDA-responses were not detectable with our recording techniques and/or; (2) the desensitizing component was more effectively blocked by NAAG. NAAG's antagonism at the NMDAR was not surmountable by increased NMDA concentration (Figure 5). Moreover, it is possible that NAAG may have less effect on extra-synaptic than synaptic receptors.

The two sets of pooled data were each fit to a curve derived from a logistic function. Similar $\mathrm{EC}_{50} \mathrm{~s}$ were calculated for each set. When NMDA was applied alone the $\mathrm{EC}_{50}=86 \mu \mathrm{M}$; when applied with NAAG $(20 \mu \mathrm{M})$ the $\mathrm{EC}_{50}=55 \mu \mathrm{M}(P<0.005)$. The lower $\mathrm{EC}_{50}$ in the presence of NAAG suggests that antagonism by NAAG was not due to a reduction in receptor affinity for NMDA. It is possible that the apparent increase in affinity for NMDA was due to a partial breakdown of NAAG to glutamate, which activated the NMDAR.

\section{Effect of NAAG on Dissociated Neurons}

Dissociated CA1 pyramidal neurons from mature rat brains were used to explore the effects of NAAG on fully differentiated neurons. With this procedure, the neurons preserve their dendritic structure proximal to the soma. Furthermore, the neurons are largely devoid of glial ensheathments but maintain their intact synaptic buttons. Whole-cell voltage-clamp recordings were made from a total of 26 isolated pyramidal neurons. We found that the bath application of NMDA $(100 \mu \mathrm{M})$ and glycine $(1 \mu \mathrm{m})$ induced an inward current of $550 \mathrm{pA}( \pm 110 \mathrm{pA})$. Simultaneous application of NMDA $(100 \mu \mathrm{m})$ and NAAG $(20 \mu \mathrm{m})$ reduced NMDAR current by $42 \pm 13.5 \%(P<0.005 ; n=9$; 
a

A1 $\operatorname{NMDA}(100 \mu \mathrm{M})$

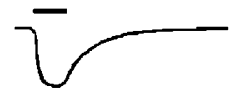

$\frac{\mid}{20} \sec$

A2 $\operatorname{NMDA}(1000 \mu \mathrm{M})$

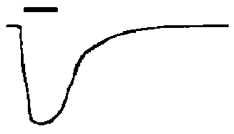

$\operatorname{NMDA}(1000 \mu \mathrm{M})+\mathrm{NAAG}(20 \mu \mathrm{M})$

b

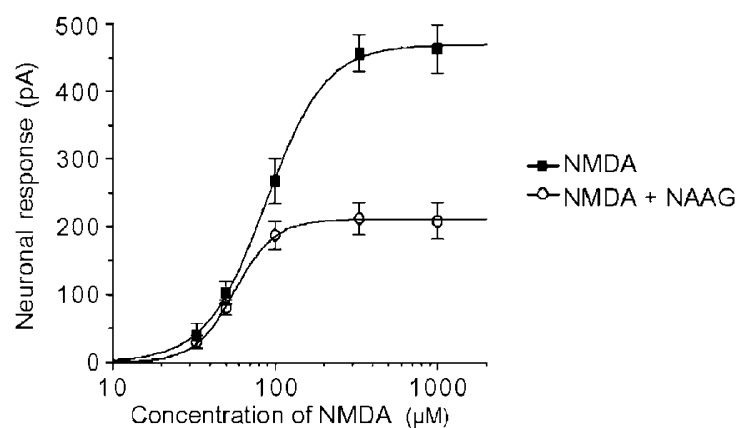

Figure 5 Effect of NAAG on dissociated CAI pyramidal neuron. (a) Traces from digitized recordings of CAI pyramidal neurons during bath application of NMDA. Two responses to NMDA are illustrated (AI: NMDA $100 \mu \mathrm{M}$ and A2: NMDA $1000 \mu \mathrm{M}$; left column) and both are reduced when NAAG ( $20 \mu \mathrm{M}$; right column) is added together with the NMDA. (b) Dose-response relationships for NMDA and for NMDA together with NAAG $(20 \mu \mathrm{M})$. Responses reflect the peak value. Five neurons were tested for each concentration and error bars represent SEM.

Figure $6 c$ ). This reduction was partially overcome by the addition of $10 \mu \mathrm{m}$ of glycine ( $n=12$; Figure $6 \mathrm{~d})$.

\section{Desensitization}

Given the weak agonist effects of NAAG at the NMDAR previously described by Westbrook et al (1986), it is possible that NAAG exerts its inhibition by desensitizing the NMDAR. We applied NAAG $(20 \mu \mathrm{M})$ simultaneously with NMDA to obtain the dose/response curve using the same paradigm as described above. While this protocol may underestimate the antagonistic actions of NAAG on NMDAR function, it is unlikely to produce a NAAGmediated desensitization by acting as a weak agonist at the NMDAR. Additionally, the response to NMDA $(100 \mu \mathrm{M})$ was compared to the response to NMDA $(100 \mu \mathrm{M})$ after a continuous bath application of a low dose of NMDA $(2 \mu \mathrm{M}$; $n=3$ ) to desensitize the receptor (data not shown). The latter dose of NMDA was too low to evoke observable currents by itself (note the $\mathrm{EC}_{50}=86 \mu \mathrm{M}$ ). One can also argue that the lack of desensitization of a low dose of NMDA $(2 \mu \mathrm{M} ; n=3)$ may be due to the slow perfusion system used in our paradigm. Again, there was no difference in the response to $100 \mu \mathrm{M}$ NMDA after preapplication of $2 \mu \mathrm{M}$ NMDA. Thus, desensitization by weak a

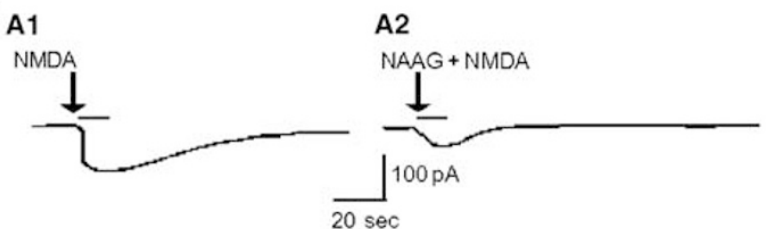

b

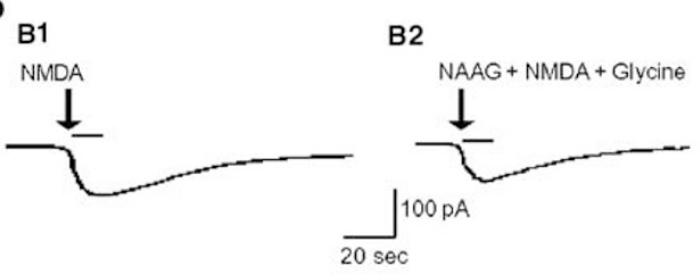

C

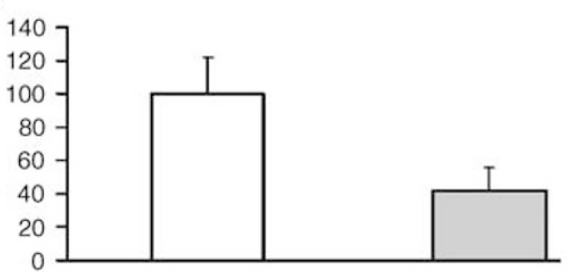

d D1

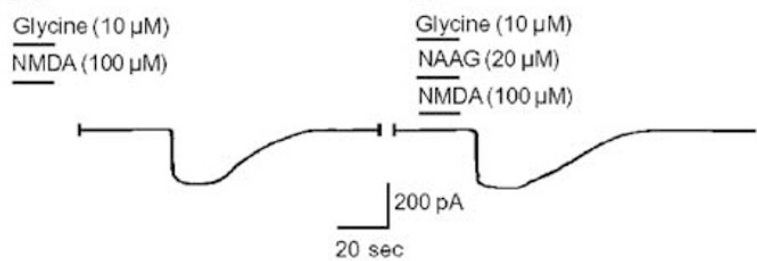

e

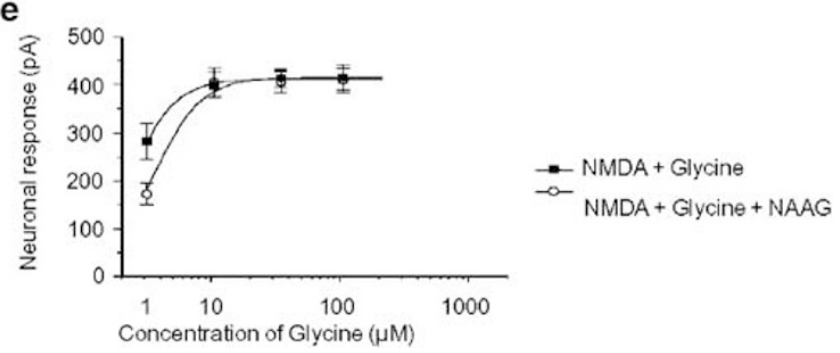

Figure 6 Antagonism of NAAG is reversed by glycine. (a) Local application of NMDA on a pyramidal dissociated neuron from CAI hippocampus. NMDA $(100 \mu \mathrm{M})$ was applied for $500 \mu \mathrm{s}(\mathrm{Al})$. The same experiment was carried out in the presence of NAAG $(20 \mu \mathrm{M})$ in the bath. (b) Local application of NMDA on a pyramidal dissociated neuron from CAI hippocampus. NMDA (I00 $\mu$ M) was applied for $500 \mu$ s (A.I). The same experiment was carried out in the presence of NAAG $(20 \mu \mathrm{M})$ and glycine $(10 \mu \mathrm{M})$. (c) Summary histogram showing the normalized EPSC amplitude reduction (mean \pm standard error) produced by NAAG $(n=9$; $p \leqslant 0.01$ ). The addition of glycine to the ACSF containing NMDA and NAAG reversed the antagonism of NAAG. (d) Amplitude of the inward current response to the perfusion with glycine $(10 \mu \mathrm{M})$ together with NMDA $(100 \mu \mathrm{M} ; \mathrm{Al})$ is unaffected by the addition of NAAG $(20 \mu \mathrm{M} ; \mathrm{A} 2)$. The dose-response relationship for glycine and NMDA (100 $\mu \mathrm{M})$ and for glycine, NMDA $(100 \mu \mathrm{M})$ and NAAG $(20 \mu \mathrm{M})$.

agonist activity of NAAG is an unlikely mechanism for the antagonism observed with bath application.

\section{Addition of Glycine}

Glycine is a co-agonist at the NMDAR. A decrease in glycine's effects at the glycine site at the NMDAR can reduce 
the maximal activation of the NMDAR by NMDA (Johnson and Ascher, 1987; Kleckner and Dingledine, 1988; Mayer et al, 1989; Thomson et al, 1989; Bergeron et al, 1998). Accordingly, we examined the possibility that NAAG might exert a noncompetitive effect by acting at this site. The response to an application of NMDA $(100 \mu \mathrm{M})$ and glycine $(10 \mu \mathrm{M})$ was compared to a similar application with the addition of NAAG $(20 \mu \mathrm{M} ; n=3$; Figure $6 \mathrm{~d})$. The amplitude of the response was unchanged by the addition of NAAG. The decay of the response was noticeably slower in the presence of NAAG (see also Figure 4a), most likely as a result of the metabolism of NAAG to glutamate by GCP II present in the slice.

Two dose/response curves for glycine were obtained with a bath application of NMDA $(100 \mu \mathrm{M})$. The curve for the control condition in the absence of NAAG was compared to the curve obtained in the presence of NAAG $(20 \mu \mathrm{M}$; Figure 6e). As endogenous glycine was present in the acute slice at a concentration sufficient to partially activate NMDA-dependent responses (Bergeron et al, 1998), only the upper portion of a complete glycine dose/response curve $(>50 \%)$ was observable. At high doses of glycine $(\geqslant 10 \mu \mathrm{M})$, the antagonism by NAAG $(20 \mu \mathrm{M})$ was no longer observable (Figure 6e). This may explain the absence of antagonistic effects of NAAG at the NMDAR observed in culture preparations that included glycine in the culture medium (Westbrook et al, 1986) as the glycine transporter, GlyT1, maintains subsaturating concentrations of glycine at the NMDAR in the acute hippocampal slice (Berger and Schwab, 1996).

Glycine's ability to overcome the NAAG blockade might result from a competitive antagonism by NAAG at the glycine site of the NMDAR. When two curves derived from a logistic function were fit to the glycine dose/response data, the apparent $\mathrm{EC}_{50}$ for glycine plus NAAG $(20 \mu \mathrm{M})$ is about one half of the $\mathrm{EC}_{50}$ for glycine alone. Both curves are constrained by assuming identical minimal glycine responses to $10 \mu \mathrm{M}$ glycine and identical steepness factors.

\section{Ligand Binding}

Given the noncompetitive antagonism of NMDAR currents by NAAG that can be reversed by adding glycine, we then examined the interactions of NAAG with the glycine modulatory site on the NMDAR by ligand binding methods in cortical synaptic membranes. MDL 105,519 is a wellcharacterized antagonist ligand with high affinity for the glycine site (Grimwood et al, 1992; Baron et al, 1996). As shown in Figure 7a, glycine displaced [3H]MDL 105,579 with a submicromolar affinity whereas NAAG caused minimal inhibition of binding at $1 \mathrm{mM}$. Thus, NAAG does not act directly at the glycine modulatory site. Nevertheless, when $[3 \mathrm{H}]$ glycine was used as the ligand (in the presence of $100 \mu \mathrm{M}$ strychnine; Figure 7b), NAAG caused an inhibition of binding with $\mathrm{IC}_{50}$ of $31 \mu \mathrm{M}$ with a Hill coefficient less than half that observed with glycine. Although Scatchard analysis of the effects of $100 \mu \mathrm{M}$ NAAG on [3H]glycine binding in cortical synaptic membranes revealed no significant change in $K_{\mathrm{D}}$ with a significant reduction $(p<0.05)$ in $B_{\max }$, interpretation of this analysis is limited by the low affinity of the glycine binding site. Thus, a threeto five-fold reduction in affinity induced by NAAG could
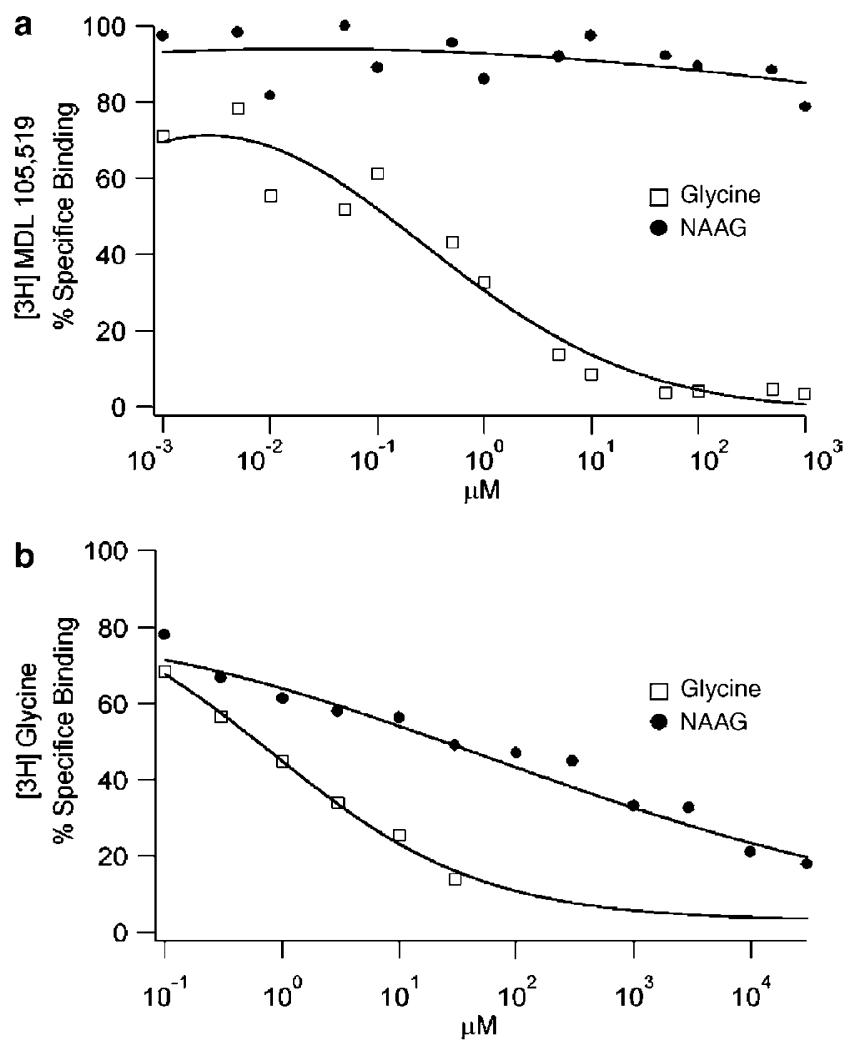

Figure 7 Effects of NAAG on the strychnine insensitive glycine site in cortical synaptic membranes. (a) Effects of glycine and NAAG on the specific binding of $4 \mathrm{nM}$ of the glycine modulatory site anatgonist ligand, $[3 \mathrm{H}] \mathrm{MDL}$ 105,5 19 , in a lysed P2 preparation from rat cerebral cortex. Note that glycine displacement is consistent with a bimolecular interaction whereas NAAG exhibits negligible inhibition at I mM. (b) Effects of glycine and NAAG on the specific binding of $[3 \mathrm{H}]$ glycine in the presence of strychnine. Note the $I_{50}$ for glycine is $560 \mathrm{nM}$ and for NAAG is $31 \mu \mathrm{M}$. The Hill coefficient for glycine is 0.99 and for NAAG is 0.47 . The slopes differ significantly $(p<0.01)$ with the NAAG inhibition consistent with negative cooperativity.

result in an apparent reduction of $B_{\max }$ due to the rapid dissociation of the $[3 \mathrm{H}]$ glycine at the reduced affinity. This is in accordance with our electrophysiological data showing reversal of the NAAG inhibition at high concentrations of glycine. This is consistent with an inhibitory allosteric modulation of glycine binding.

\section{Role of Group 2 Metabotropic Glutamate Receptors}

NAAG was found to be a potent agonist of mGluR3 autoreceptors on presynaptic terminals (Wroblewska et al, 1993). This implies that NAAG has the potential to suppress synaptic release of glutamate. Accordingly, we then examined the effects of the potent and selective group 2 metabotropic glutamate autoreceptor antagonist LY-341495. We recorded from CA1 pyramidal neurons and then isolated the NMDAR current as previously described. We found that in 16 of the 19 neurons tested, LY-341495 had no significant effect on the NMDAR component of the EPSC $(14.7 \pm 8.7 \% \quad(P>0.05 ; n=16$; data not shown $))$. The simultaneous application of NAAG $(20 \mu \mathrm{m})$ with LY341495 reduced the NMDAR current $(39.8 \pm 18.2 \%$; $P<0.005 ; n=12$, data not shown). In three neurons NAAG 
had no effect. These results are consistent with the observation that in the CA1 area of the hippocampus, the decrease of the activation of NMDAR is not the result of a decrease of the release of glutamate from the presynaptic terminal through activation of mGluR3 receptors.

\section{DISCUSSION}

The present study provides evidence that NAAG directly modulates excitatory synaptic neurotransmission via an action on NMDAR located on CA1 pyramidal neurons. In our paradigm (whole-cell voltage-clamp technique) and at the dose used in our series of experiments $(20 \mu \mathrm{M})$, NAAG inhibits the isolated NMDAR-dependent currents in CA1 pyramidal neurons evoked by bath application of NMDA, by picrospitzer applications of NMDA or by synaptic release of glutamate from Schaffer collaterals. The inhibitory effects of NAAG appeared to be restricted to the NMDAR component of the EPSC, sparing the AMPAR component evoked by stimulation of the Schaffer collaterals. This effect is inconsistent with a presynaptic site of action of NAAG, which would have similar inhibitory effects on both currents. The absence of a potential presynaptic action of NAAG is further confirmed by the results of the pairedpulse paradigm.

Inhibitory effects of NAAG on the NMDAR currents demonstrated with the Schaffer collateral stimulation to the CA1 pyramidal neurons were replicated with direct activation of the receptor with NMDA bath application. However, this method does have the limitation of activating NMDAR throughout the slice. To address this limitation, the effects of NAAG in inhibiting NMDA evoked currents was confirmed in acutely dissociated adults CA1 pyramidal neurons and by picrospritzing of NMDA on identified neurons in the acute hippocampal slice. Inhibitory effects of NAAG appear to be all-or-none. We do not know the reason for that, however, there is precedent for NMDAR inhibition where zinc has a steep dose-response curve of NR2A of approximately 80\% (Paoletti et al, 1997; Traynelis et al, 1998).

The antagonistic effects of NAAG are not related to its action at the mGluR3 receptor, which can downregulate glutamate release (Wroblewska et al, 1997). A decrease of synaptic glutamate release is inconsistent with our observations that AMPAR-EPSCs are not affected by NAAG. Moreover, in the presence of the selective and potent group 2 metabotropic receptor antagonist LY-341495, NAAG still reduced the NMDAR current following stimulation of the Schaffer collaterals. Indeed, group 2 metabotropic glutamate receptors are unlikely to be involved in the modulation of the CA3 to CA1 synapse examined in this study since mGluR3 receptor activation does not affect Schaffer collateral-evoked EPSCs recorded from CA1 pyramidal cells nor is there appreciable expression of mGluR3 RNA in either CA1 or CA3 pyramidal cells (Ohishi et al, 1993; Gereau and Conn, 1995). Our results with the paired-pulse stimulation are also consistent with a postsynaptic action of NAAG. These findings differ from those of Lea et al (2001) who examined the effects of NAAG in the neurons in the dentate gyrus. In this sector, mGluR3 modulates excitatory neurotransmission, and it appeared that the effects of
NAAG were mediated by the mGluR3 receptors. Effects of NAAG on AMPAR currents were difficult to evaluate because of the small number of observations $(n=3$; Lea et al, 2001). However, we acknowledge that NAAG may have multiple actions, depending upon the neuron studied.

Given the weak agonist effects $(300 \mu \mathrm{M})$ reported for NAAG on cultured neurons (Westbrook et al, 1986), a potential explanation of our findings is that NAAG is desensitizing the NMDAR. However, the concentrations of NAAG used in our studies were much lower than those reported to activate NMDAR. Furthermore, at the concentration used $(20 \mu \mathrm{M})$, no depolarizing effects of NAAG were observed. The hypothesized desensitization could not be demonstrated by prior treatment of the slices with subthreshold concentrations of NMDA $(2 \mu \mathrm{M})$. Furthermore, simultaneous applications of NAAG and NMDA to avoid desensitization due to prior exposure to NAAG still revealed the inhibitory effect of NAAG on the NMDAR currents.

An important finding that may speak to the mechanism of action of NAAG is that its inhibitory effect on NMDAR can be reversed by increased concentrations of the co-agonist glycine. This effect may provide an explanation for reports that NAAG is a weak agonist at NMDAR as the studies were carried out in the presence of glycine. However, ligand binding studies with the glycine modulatory site high affinity antagonist [3H]MDL 105,529 indicate that NAAG does not directly compete at the recognition site. Rather, the binding data with $[3 \mathrm{H}]$ glycine in the presence of strychnine suggest that NAAG allosterically reduces the affinity of the site for glycine on the NR1 subunit. Spermine has been reported to increase the affinity of the glycine site for glycine in cultured hippocampal neurons (Benveniste and Mayer, 1993), thus providing a precedent for allosteric modulation at the glycine site. Whether the effects of NAAG reflect a bimolecular interaction with NMDAR or result from a covalent modification (ie phosphorylation) remains unresolved. However, the rapid onset and offset of the effect would favor the former.

It is unclear whether the effects of NAAG can be extended beyond the CA1 pyramidal neurons that were the object of this study. Other reports are in contrast with our findings. These neurons express predominately NR2A subunit (Freund and Buzsaki, 1996). Nevertheless, more potent inhibition of NMDAR currents were previously reported in GABAergic interneurons in the CA1 sector of the rat hippocampus, inhibiting the development of long-term potentiation (Grunze et al, 1996) and reducing the climbing fiber response in the acute cerebellar slice (Sekiguchi et al, 1989). Notably, Losi et al (2004) did not observe NMDAR antagonism by NAAG in cultured cerebellar granule cells as was also the case for cultured motoneurons (Westbrook et al, 1986). Whether these disparities reflect differences in the characteristics of the NMDAR on these neurons or the effects of high ambient glycine in the culture medium remains to be determined. In the acute hippocampal slice, GlyT1 maintains subsaturating concentrations of glycine at synaptic NMDAR, perhaps optimizing the ability to observe the inhibitory effects of NAAG.

NAAG may be included in a growing list of endogenous substances, including magnesium, zinc, protons, phenylethanolamines or kynurenic acid (Dingledine et al, 1999) 
that negatively modulate NMDAR function. This modulation may be important in the regulation of synaptic plasticity as well as protection of neurons against excitotoxicity during periods of pathologically high glutamatergic synaptic activity (Greene et al, 2000).

The observation that NAAG reduces NMDAR current is an important step in our understanding of the role of NAAG in neuroprotection (Slusher et al, 1999) and in a variety of human diseases such as schizophrenia (Tsai et al, 1995). Clarification of the physiological action of NAAG has proved to be complicated and controversial. Owing to its wide distribution in the CNS, NAAG may have several actions on neurons. The present results demonstrate that NAAG modulates excitatory neurotransmission by decreasing NMDAR mediated currents through a mechanism that is reversible by glycine. It is noteworthy that the glycine transporter (Bergeron et al, 1998) and serine racemase (De Miranda et al, 2000) that regulate the availability of agonist for the NMDAR glycine site are expressed in astrocytes, which also express glutamate carboxypeptidase II that catabosizes NAAG.

\section{ACKNOWLEDGEMENTS}

RB is supported by a Senior Research Fellowship from the Canadian Institutes on Health Research and by a grant from the Young Investigator Award from the National Alliance for Research on Schizophrenia and Depression (NARSAD). JTC is supported by the NARSAD Hilton Senior Investigator Award and as PHS grant MH 51290 and MH606450. GT is supported by a Young Investigator Award from NARSAD and the Stanley Foundation. RWG is supported by the Department of Veterans Affairs. This research is also supported by NIMH Silvio Conte Neuroscience of Schizophrenia Center. We thank Melissa Mudrick for technical support, and Fran McNeil for secretarial assistance.

\section{REFERENCES}

Amaral DG, Witter MP (1989). The three-dimensional organization of the hippocampus formation: a review of anatomical data. Neuroscience 31: 571-591.

Baron BM, Siegel BW, Harrison BL, Gross RS, Hawes C, Towers P (1996). [3H]MDL105,519, a high-affinity radioligand for the $\mathrm{N}$-methyl-D-aspartate receptor-associated glycine recognition site. J Pharmacol Exp Ther 279: 62-68.

Benveniste M, Mayer ML (1993). Multiple effects of spermine on $\mathrm{N}$-methyl-D-aspartic acid receptor responses of rat cultured hippocampal neurones. J Physiol 464: 131-163.

Berger UV, Carter RE, McKee M, Coyle JT (1995a). The immunocytochemical localization of $\mathrm{N}$-acetylaspartyl glutamate, its hydrolysing enzyme NAALADase, and the NMDR-1 receptor at a vertebrate neuromuscular junction. Neuroscience 64: 847-850.

Berger UV, Carter RE, McKee M, Coyle JT (1995b). N-acetylated alpha-linked acidic dipeptidase is expressed by non-myelinating Schwann cells in the peripheral nervous system. J Neurocytol 24: 99-109.

Berger UV, Luthi-Carter R, Passani LA, Elkabes S, Black I, Konradi C et al (1999). Glutamate carboxypeptidase II is expressed by astrocytes in the adult rat nervous system. J Comp Neurol 415: $52-64$.
Berger UV, Schwab ME (1996). N-acetylated alpha-linked acidic dipeptidase may be involved in axon-Schwann cell signaling. J Neurocytol 25: 499-512.

Bergeron R, Meyer TM, Coyle JT, Greene RW (1998). Modulation of the $N$-methyl-D-aspartate receptor function by glycine transport. Proc Natl Acad Sci USA 95: 15730-15734.

Blanton MG, Lo Turco JJ, Kriegstein AR (1989). Whole cell recording from neurons in slices of reptilian and mammalian cerebral cortex. J Neurosci Methods 30: 203-210.

Carter RE, Feldman AR, Coyle JT (1996). Prostate-specific membrane antigen is a hydrolase with substrate and pharmacologic characteristics of a neuropeptidase. Proc Natl Acad Sci USA 93: 749-753.

Coyle JT (1997). The nagging question of the function of $\mathrm{N}$-acetylaspartylglutamate. Neurobiol Dis 4: 231-238.

De Miranda J, Santoro A, Engelender S, Wolosker H (2000). Human serine racemase: molecular cloning, genomic organization and functional analysis. Gene 256: 183-188.

Dingledine R, Borges K, Bowie D, Traynelis SF (1999). The glutamate receptor ion channels. Pharmacol Rev 51: 7-61.

Freund TF, Buzsaki G (1996). Interneurons of the hippocampus. Hippocampus 6: 347-470.

Frondoza CG, Logan S, Forloni G, Coyle JT (1990). Production and characterization of monoclonal antibodies to $N$-acetyl-aspartylglutamate. J Histochem Cytochem 38: 493-502.

Gereau IV RW, Conn PJ (1995). Multiple presynaptic metabotropic glutamate receptors modulate excitatory and inhibitory synaptic transmission in hippocampal area CA1. J Neurosci 15: 6879-6889.

Greene R, Bergeron R, McCarley R, Coyle JT, Grunze H (2000). Short-term and long-term effects of $\mathrm{N}$-methyl-D-aspartate receptor hypofunction. Arch Gen Psychiatry 57: 1180-1181.

Grimwood S, Moseley AM, Carling RW, Leeson PD, Foster AC (1992). Characterization of the binding of [3H]L-689,560, an antagonist for the glycine site on the $N$-methyl-D-aspartate receptor, to rat brain membranes. Mol Pharmacol 41: 923-930.

Grunze HC, Rainnie DG, Hasselmo ME, Barkai E, Hearn EF, McCarley RW et al (1996). NMDA-dependent modulation of CA1 local circuit inhibition. J Neurosci 16: 2034-2043.

Halsted CH, Ling EH, Luthi-Carter R, Villanueva JA, Gardner JM, Coyle JT (1998). Folylpoly- $\gamma$-glutamate carboxypeptidase from pig jejunum. Molecular characterization and relation to glutamate carboxypeptidase II. J Biol Chem 273: 20417-20424.

Johnson JW, Ascher P (1987). Glycine potentiates the NMDA response in cultured mouse brain neurons. Nature 325: 529-531.

Kandel ER, Schwartz JH, Jessell TM (2000). Principle of Neural Science, 4th edn. McGraw-Hill Co.: New York. pp 281.

Kleckner NW, Dingledine R (1988). Requirements for glycine in activation of NMDA-receptors expressed in Xenopus oocytes. Science 241: 835-837.

Lea IV PM, Wroblewka B, Sarvey JM, Neale JH (2001). NAAG rescues LTP from blockade in rat dentate gyrus via the type 3 metabotropic glutamate receptor. J Neurophysiol 85: 1097-1106.

Losi G, Vicini S, Neale J (2004). NAAG fails to antagonize synaptic and extrasynaptic NMDA receptor in cerebellar granule neurons. Neuropharmacology 46: 490-496.

Lowry OH, Rosebrough NJ, Farr AL, Randall RJ (1951). Protein measurement with the Folin phenol reagent. J Biol Chem 193: 265-275.

Mayer ML, Vyklicky Jr L, Clements J (1989). Regulation of NMDA receptor desensitization in mouse hippocampal neurons by glycine. Nature 338: 425-427.

Moffett JR, Cassidy M, Namboodiri MA (1989). Selective distribution of $\mathrm{N}$-acetylaspartylglutamate immunoreactivity in the extrapyramidal system of the rat. Brain Res 494: 255-266.

Moffett JR, Namboodiri MA (1995). Differential distribution of $\mathrm{N}$-acetylaspartylglutamate and $\mathrm{N}$-acetylaspartate immunoreactivities in rat forebrain. J Neurocytol 24: 409-433. 
Moffett JR, Palkovits M, Namboodiri A, Neale JH (1994). Comparative distribution of $\mathrm{N}$-acetylaspartylglutamate and $\mathrm{GAD}_{67}$ in the cerebellum and precerebellar nuclei of the rat utilizing enhanced carbodiimide fixation and immunohistochemistry. J Comp Neurol 347: 598-618.

Neale JH, Bzdega T, Wroblewska B (2000). N-Acetylaspartylglutamate: the most abundant peptide neurotransmitter in the mammalian central nervous system. J Neurochem 75: 443-452.

Ohishi O, Shigemoto R, Nakanishi S, Mizuno N (1993). Distribution of the mRNA for a metabotropic glutamate receptor (mGluR3) in the rat brain: an in situ hybridization study. J Comp Neurol 335: 252-266.

Paoletti P, Ascher P, Neyton J (1997). High-affinity zinc inhibition of NMDA NR1-NR2A receptors. J Neurosci 17: 5711-5725.

Passani LA, Vonsattel JP, Coyle JT (1997). Distribution of $\mathrm{N}$ acetylaspartylglutamate immunoreactivity in human brain and its alteration in neurodegenerative disease. Brain Res 772: 9-22.

Sekiguchi M, Okamoto K, Sakai Y (1989). Low-concentration $N$ acetylaspartylglutamate suppresses the climbing fiber response of Purkinje cells in guinea pig cerebellar slices and the responses to excitatory amino acids of Xenopus laevis oocytes injected with cerebellar mRNA. Brain Res 482: 87-96.

Serval V, Barbeito L, Pittaluga A, Cheramy A, Lavielle S, Glowinski J (1990). Competitive inhibition of $N$-acetylated-alpha-linked acidic dipeptidase activity by $\mathrm{N}$-acetyl-L-aspartyl-beta-linked L-glutamate. J Neurochem 55: 39-46.

Slusher BS, Robinson MB, Tsai G, Simmons ML, Richards SS, Coyle JT (1990). Rat brain $\mathrm{N}$-acetylated alpha-linked acidic dipeptidase activity. Purification and immunologic characterization. J Biol Chem 265: 21297-21301.

Slusher BS, Tsai G, Yoo G, Coyle JT (1992). Immunocytochemical localization of the $\mathrm{N}$-acetyl-aspartyl-glutamate (NAAG) hydrolyzing enzyme $N$-acetylated alpha-linked acidic dipeptidase (NAALADase). J Comp Neurol 315: 217-229.

Slusher BS, Vornov JJ, Thomas AG, Hurn PD, Harukuni I, Bhardwaj A et al (1999). Selective inhibition of NAALADase, which converts NAAG to glutamate, reduces ischemic brain injury. Nat Med 5: 1396-1402.

Stauch BL, Robinson MB, Forloni G, Tsai G, Coyle JT (1989). The effects of $\mathrm{N}$-acetylated alpha-linked acidic dipeptidase (NAALADase) inhibitors on [3H]NAAG catabolism in vivo. Neurosci Lett 100: $295-3000$.
Thomson AM, Walker VE, Flynn DM (1989). Glycine enhances NMDA-receptor mediated synaptic potentials in neocortical slices. Nature 338: 422-424.

Traynelis S, Burgess RMF, Zheng F, Lyuboslavsky P, Powers JL (1998). Control of voltage-independent zinc inhibition of NMDA receotirs by NR1 subunit. J Neurosci 18: 6163-6175.

Trombley PQ, Westbrook GL (1990). Excitatory synaptic transmission in cultures of rat olfactory bulb. J Neurophysiol 64: 598-606.

Tsai G, Forloni G, Robinson MD, Stauch BL, Coyle JT (1988). Calcium-dependent evoked release of $\mathrm{N}-[3 \mathrm{H}]$ acetylaspartylglutamate from the optic pathway. J Neurochem 51: 1956-1959.

Tsai G, Passani LA, Slusher BS, Carter R, Baer L, Kleinman JE et al (1995). Abnormal excitatory neurotransmitter metabolism in schizophrenic brains. Arch Gen Psychiatry 52: 829-836.

Tsai G, Slusher BS, Sim L, Coyle JT (1993). Immunocytochemical distribution of $\mathrm{N}$-acetylaspartylglutamate in the rat forebrain and glutamatergic pathways. J Chem Neuroanat 6: 277-292.

Tsai G, Stauch BL, Vornov JJ, Deshpande JK, Coyle JT (1990). Selective release of $\mathrm{N}$-acetylaspartylglutamate from rat optic nerve terminals in vivo. Brain Res 518: 313-316.

Valivullah HM, Lancaster J, Sweetnam PM, Neale JH (1994) Interactions between $N$-acetylaspartylglutamate and AMPA, kainite, and NMDA binding sites. J Neurochem 63: 1714-1719.

Westbrook GL, Mayer ML, Namboodiri MA, Neale JH (1986). High concentrations of $\mathrm{N}$-acetylaspartylglutamate (NAAG) selectively activate NMDA receptors on mouse spinal cord neurons in cell culture. J Neurosci 6: 3385-3392.

Williamson LC, Neale JH (1988). Calcium-dependent release of $\mathrm{N}$ acetylaspartylglutamate from retinal neurons upon depolarization. Brain Res 475: 151-155.

Wroblewska B, Wroblewski JT, Pshenichkin S, Surin A, Sullivan SE, Neale JH (1997). N-acetylaspartylglutamate selectively activates mGluR3 receptors in transfected cells. J Neurochem 69: 174-181.

Wroblewska B, Wroblewski JT, Saab OH, Neale JH (1993). Nacetylaspartylglutamate inhibits forskolin-stimulated cyclic AMP levels via a metabotropic glutamate receptor in cultured cerebellar granule cells. J Neurochem 61: 943-948.

Zollinger M, Brauchli-Theotokis J, Gutteck-Amsler U, Do KQ, Streit P, Cuenod M (1994). Release of $\mathrm{N}$-acetylaspartylglutamate from slices of rat cerebellum, striatum, and spinal cord, and the effect of climbing fiber deprivation. J Neurochem 63: 1133-1142. 